\title{
The Nanotechnology Field Research Team Update
}

T n 2006, NIOSH established a Nanotechnology Field Research Team to expand its knowledge and understanding of the potential health and safety risks that workers may encounter during the research, production, and use of engineered nanomaterials. This effort has complimented NIOSH's extensive laboratory-based research program, as well as helped NIOSH identify and more fully understand the variety of work processes used to generate and manufacture engineered nanomaterials. It has also provided NIOSH with the opportunity to observe and evaluate work practices and engineering controls used to ensure worker health and safety in the nanotechnology industry.

$\mathrm{NIOSH}$ has conducted site visits to several facilities around the country that are involved in the research, manufacture, or use of various types of nanomaterials including, metal and metal oxide nanoparticles, carbon nanofibers, electrospun nanofibers, quantum dots, fullerenes, and nanocomposites. As a result, NIOSH obtained valuable information that is being used to assist in developing workplace guidance documents to protect nanotechnology workers from occupational injury and illness, and has learned that:

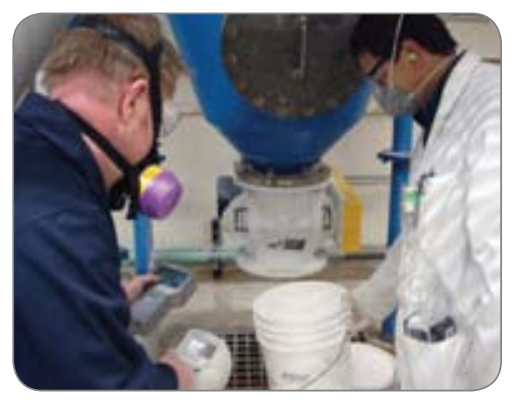

- basic particle counting and sizing instruments can be used to identify emissions from nanomaterial processes,

- careful interpretation of the particle data is needed to differentiate between incidental (background) and process-related nanoparticles, and

- engineering controls do minimize workplace exposure to engineered nanoparticles.

Companies interested in receiving a visit by the Field Research Team are encouraged to contact NIOSH. All site visits are initiated by the respective companies and are completely voluntary. This program is fully funded by NIOSH; therefore, there is no monetary cost to the participant. Three companies who have voluntarily received site evaluations from the NIOSH Field Research Team were recently interviewed by Nanowerk, LLC for its August/September 2007 issue of Nanorisk (www.nanorisk.org/). Overall, they described the collaboration as beneficial, and encouraged other companies to take advantage of NIOSH's expertise, services, instrumentation, and unbiased assessments.

For more information about occupational safety and health topics pertaining to engineered nanomaterials, including fact sheets about the Field Research effort and other nanotechnology research programs, please visit the NIOSH nanotechnology topic page at www.cdc.gov/niosh/topics/nanotech. To discuss the possibility of receiving a site evaluation by the NIOSH Field Research Team, contact Charles Geraci, Ph.D., CIH at (513) 533-8339, CGeraci@cdc.gov or Mark Methner, Ph.D., CIH at (513) 841-4325, MMethner@cdc.gov.

DEPARTMENT OF HEALTH AND HUMAN SERVICES

Centers for Disease Control and Prevention

National Institute for Occupational Safety and Health
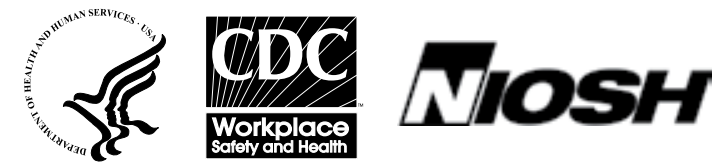
To receive other documents or other information about occupational safety and health topics, contact $\mathrm{NIOSH}$ at

Telephone: 1-800-CDC-INFO (1-800-232-4636)

TTY: 1-888-232-6348.E-mail: cdcinfo@cdc.gov

or visit the NIOSH Web site at www.cdc.gov/niosh

For a monthly update on news at NIOSH, subscribe to NIOSH eNews by visiting www.cdc.gov/ niosh/eNews.

This document is in the public domain and may be freely copied or reprinted.

Mention of any company, product, or commercial publication does not constitute endorsement by $\mathrm{NIOSH}$. In addition, citations to Web sites external to NIOSH do not constitute NIOSH endorsement of the sponsoring organizations or their programs or products. Furthermore, NIOSH is not responsible for the content of these Web sites.

DHHS (NIOSH) Publication No. 2008-120

SAFER • HEALTHIER • PEOPLE ${ }^{\text {TM }}$

February 2008

\section{DEPARTMENT OF HEALTH AND HUMAN SERVICES}

Centers for Disease Control and Prevention

National Institute for Occupational Safety and Health

4676 Columbia Parkway

Cincinnati, OH 45226-1998 